\title{
THE SUCCESSFUL REMOVAL OF AN ANTERIOR MEDIASTINAL TERATOMA FROM AN INFANT
}

BY

\author{
F. STARER \\ From the Thoracic Surgical Unit, Leicester
}

(RECEIVED FOR PUBLICATION JANUARY 28, 1952)

Teratomas of the anterior mediastinum are rarely discovered in children, and there are so far only a few reports of their successful removal. The youngest yet recorded is that of Vervat (1949) in an 8-month-old baby. The present case is thought to be of interest because of the age of the patient and the unusual pathological features presented by the tumour.

\section{Case Report}

The patient was a baby girl aged 8 days. Pregnancy had been normal and she was delivered at full term. As the mother had previously had a pelvic floor repair, delivery was by Caesarean section. The child was limp at birth, but responded slowly to lobeline and oxygen. The following day it was noticed that she became severely cyanosed after every breast feed and that the cyanosis was only slowly relieved by oxygen.

Examination showed her to be a healthy looking infant weighing $7 \mathrm{lb} .13 \mathrm{oz}$. No external abnormalities could be detected, but there was some indrawing of the lower intercostal spaces with respiration. Percussion of the chest revealed generalized dullness and there was poor air intake. There were no other abnormal physical findings.

A radiograph of the chest on the eighth day showed a large intrathoracic opacity filling most of the right hemithorax. The heart was markedly displaced to the left (Fig. 1). A right lateral radiograph showed that this opacity was situated almost entirely in the anterior mediastinum (Fig. 2). There were irregular areas of calcification in the anterior portion of the opacity. From the findings a diagnosis of anterior mediastinal teratoma was made.

During the next two days the cyanotic attacks following feeds became worse and it was decided to try and remove the tumour. The operation was carried out when the patient was 10 days old by Mr. Gordon Cruickshank. Before operation a blood transfusion was started. Anaesthesia was induced with oxygen and cyclopropane. The fifth rib was resected through a right subscapular incision. A tumour was visible immediately the pleura was opened. It occupied nearly the entire hemithorax, and was partly solid, partly cystic. Fluid was aspirated from the cystic part to diminish its bulk, after which the mediastinal pleura

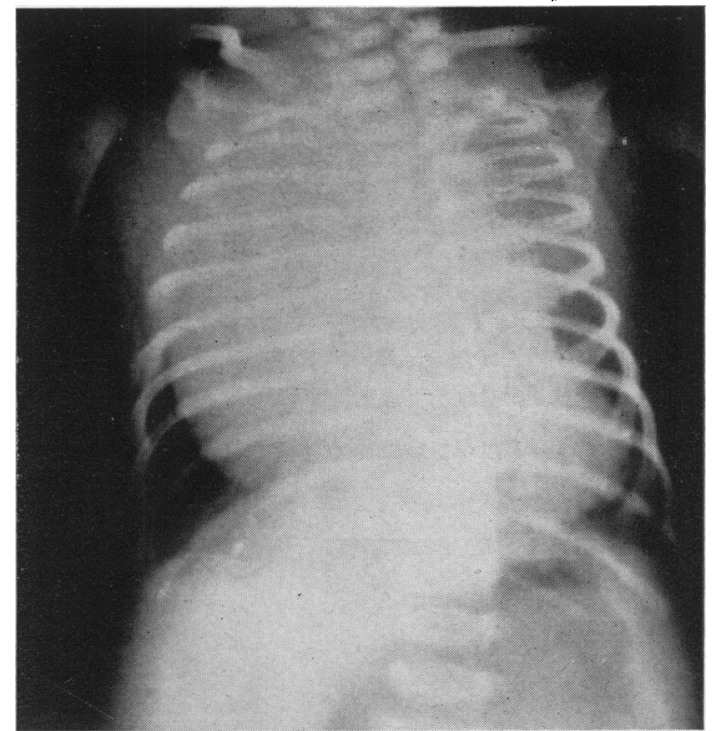

FIG. 1.-Antero-posterior radiograph of chest showing large rightsided mediastinal mass.

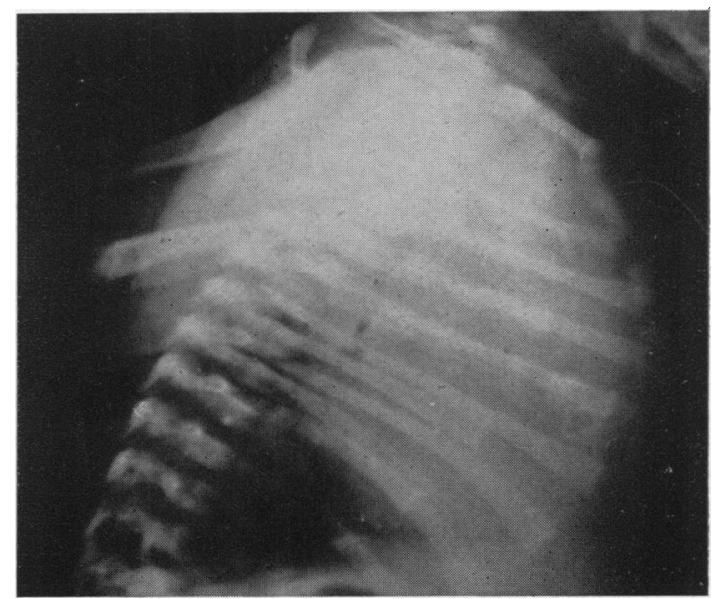

FIG. 2.-Right lateral radiograph of chest. Note areas of calcification in the anterior part of the tumour. 


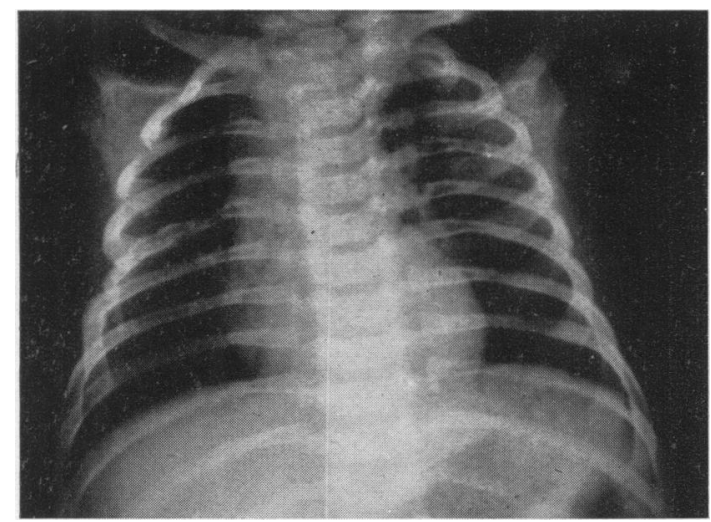

Fig. 3.-Radiograph taken six weeks after operation. Note regenerated rib.

overlying the tumour was incised and the tumour shelled out by finger without any difficulty. There was no bleeding and the lung inflated fully and easily. The chest was closed, using three layers of polythene thread and silk for the skin. Post-operative bronchoscopy was performed and the child's condition after operation was satisfactory.

The post-operative course was entirely uneventful. The baby could now take her feeds without becoming cyanosed, and the wound healed completely and rapidly.

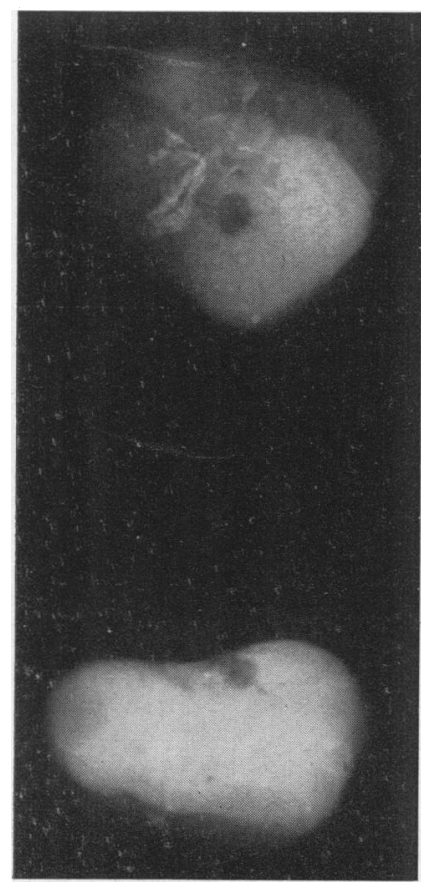

FIG. 4.-Radiographs in two planes of the specimen. Note bone formation resembling digits in the upper one.
She was discharged eight days after operation. When seen six weeks later, she had gained weight and had no further symptoms. The lung was fully expanded and there was almost complete regeneration of the excised rib (Fig. 3). At 6 months the child's weight was $17 \mathrm{lb} .6 \mathrm{oz}$., and she was well in every respect.

Pathological Report. Dr. D. B. Cruickshank reported on the tumour as follows:

The tumour measured $7 \times 6 \times 4$ $\mathrm{cm}$. and weighed $95 \mathrm{~g}$. There was a solid mass occupying one pole, while the other end con$\mathrm{s}$ is te d of intercom municating cysts. Related to one of the cysts was a small mass of solid tissue containing bone, cartilage, red mamillae and cartilaginous structures resembling incisor teeth; radiographs show that the bone in this area developed in linear fashion very suggestive of phalanges (Fig. 4).

Microscopically the following tissues could be seen in the cystic portion: thymus with Hassal's corpuscles; keratinized squamous epithelium; a myxomatous dermis with numerous hair follicles, hairs, sebaceous glands and fat cells; areas of well-formed cartilage; bone with red marrow; bundles of plain muscle; nerves; spaces lined with columnar ciliated bronchial epithelium; columnar mucous epithelium resembling intestinal type; lymphatic channels. In the solid portion of the tumour were structures resembling salivary glands. Some of these cells were relatively anaplastic and showed numerous mitotic figures. There were masses of primitive liver cells with distinctive Kupffer cells and surrounding blood; zones of neuroglia with numerous nerve cells; choroid plexus; primitive capillaries; intestinal epithelium with wellmarked circular and longitudinal muscle; cardiac muscle; fat. Tissues of all embryonic layers occurred but voluntary muscle was absent.

The grouping of tissues was generally quite random but observed correlations included: (1) highly organized skin; (2) intestinal epithelium related to longitudinal and circular muscle; (3) cerebral tissues related to cartilage and bone; (4) ciliated epithelium, mucous glands, plain muscle, cartilage and bone were grouped together; (5) bone formations were not wholly erratic and some resembled radiographically bones of the hand (or foot).

\section{Discussion}

Teratomas of the anterior mediastinum are uncommon; of 82 teratomas studied by Willis (1948), only three occurred in that position. Rusby (1944) has reviewed the entire literature on anterior mediastinal teratomas since the first paper by Gordon in 1827 up to 1939 , and was able to collect 245 cases; he adds six of his own. Laipply (1945) obtained the same figure in a review up to 1944 . It has been possible to trace 120 cases reported since 1939. Of these only two have appeared in the British literature (Fawcett, 1944; Gardner, 1950). The increasing number of reports is undoubtedly due to the wider use of routine radiological examination; e.g. Schlumberger (1946) reported 16 cases in U.S. Army personnel out of several million men radiographed during military service. Many of these cases were asymptomatic.

These tumours occur at all ages, but are rarely discovered before puberty. The reason for this is twofold. Children are not often included in mass surveys, while teratomas tend to remain asymptomatic till after puberty. It has in fact been suggested that there is an antagonism between the growth of the tumour and that of its host, possibly due 
to competition for some hormone. Nevertheless, several cases in young children do appear in the literature. Laipply mentions an anterior mediastinal dermoid in a stillborn infant. In Rusby's series the age was given in 174 and of these 17 were below 10 years. Heuer and Andrus (1940) state that $5 \cdot 5 \%$ of 217 patients were below the age of 12 . Of the present collection of 120 cases, the age was stated in five to be between 1 and 12 years (Berman, Powell and Hennessee, 1947; Fawcett, 1944; Heuer and Andrus, 1940; Maier, 1948; Rusby, 1944). Vervat (1949) reported the successful removal of a dermoid from a child of 8 months, the youngest case hitherto reported.

Teratomas have been defined by Willis (1948) as - true tumours or neoplasms composed of multiple tissues of kinds foreign to the part from which they arise'. This definition applies equally to dermoids; they will therefore be considered together here.

The pathological report revealed that the tumour was a teratoma of unusual complexity. The tissues most commonly found in these tumours are skin, teeth, nervous and lymphoid tissue and mixed glandular structures. On the other hand, liver is rare and the presence of cardiac muscle seems only to have been reported twice before (Katsurada, 1901; Schlumberger, 1946). The latter reports the presence of cardiac muscle in a malignant teratoma, and that tissue was also found in a liver metastasis.

Histologically, the tumour was highly differentiated. The degree of anatomical differentiation, however, was poor, but certain tissue relations were observed, e.g., intestinal epithelium related to longitudinal and circular muscle, cerebral tissue related to cartilage and bone. Similar relations between tissues have frequently been reported and comment has been made on them by several authors. Willis mentions the relationship between masses of central nervous system tissue, cartilage and bone and between ciliated epithelium and cartilage, and points out the frequent occurrence of lymphoid tissue in the 'submucosa' of ' intestinal ' structures. Similar tissue relations are mentioned by Schlumberger, and Needham (1942) goes so far as to state: 'Almost all smooth muscle in teratomas is clearly associated with glandular cavities. The impression is given that the development of muscle is determined by the presence of epithelium.'

The presence of definite tissue relations in teratomas appears to be fairly constant. It must be explained by any attempt to account for the origin of these interesting tumours, and may in turn provide the clue to such an attempt. It suggests that even amongst the chaos of the teratoma, some degree of control over the tissues exists. This is exercised by the influence of one tissue over another, so that these tissues still possess some ability to shape the destiny of their neighbours, a phenomenon known to the embryologist as dependent differentiation. It seems likely then that a study of normal developmental mechanics will further our understanding of the origin of the teratoma.

In recent years a great deal of work has been done on the control of growth and differentiation in the embryo; an outline of this work is given by Needham (1942). It has been shown that differentiation occurs as a result of the action of specific, hormone-like, chemical substances produced by the various embryonic tissues on cells capable of reacting to these substances. The earliest of these substances is produced by the dorsal lip of the blastopore and induces the formation of a neural axis in neighbouring tissues. This substance, known as the primary organizer, has been found to occur in practically all tissues so far examined, embryonic and adult, and can be liberated by killing the cells and denaturing their proteins. It appears to be a steroid related chemically to the sex hormones and some of the carcinogenetic hydrocarbons. The primary organizer can only produce induction of a neural axis on cells at a certain stage of their development, when they are competent to react. Further, not all cells possess the ability to form a neural axis showing regional differentiation. The ability of a tissue to undergo regional differentiation under the influence of an organizer is known as individuation. The nature of the individuation process is not yet understood. Once a neural axis is established it in turn produces substances capable of inducing differentiation in neighbouring tissues. Thus, a series of secondary and subsequent organizers have been shown to occur. Examples are the induction of the lens by the optic cup, and the production of the cartilagenous auditory capsule by the nervous elements of the ear vesicle. The latter recalls the observed correlation between cartilage and nervous tissue in teratomas.

There are then three factors essential for normal organogenesis; the organizer, tissue competence to react, and individuation. The first two acting together call into being tissues, while the third imparts to them their proper regional characters. Needham expresses his belief that "what lies behind the strange phenomena seen in the teratoma is the failure of the individuation field, at some point early in development, to control the action of the evocating substance'. It seems possible that 
excessive production of evocator substance may bring about such a failure in individuation. Teratomas can be produced in the cock's testes by the injection of zinc salts; these are known to cause denaturation of proteins and thereby release of organizer. Its action on germinal cells may produce chaotic tissue proliferation.

Schlumberger has extended this concept and advanced an ingenious explanation for the occurrence of teratomas in the anterior mediastinum. He, like Collenberg (1869), points to the close relationship of the anterior mediastinal teratomas to the tissues derived from branchial structures. Of these, the thymus 'Anlage' regularly descends into the anterior mediastinum. It contains in close relationship ecto- and endodermal structures, as well as Hassal's corpuscles whose origin is still doubtful. He suggests that degeneration of Hassal's corpuscles releases organizer which acts on embryonic cells present, causing their chaotic multiplication in the same way as zinc salts cause chaotic cell growth when injected into the cock's testes. Schlumberger concludes that 'teratoma of the anterior mediastinum may be identified more precisely as teratoma of the thymus '.

This theory accords best with the facts of experimental embryology. Many others have been propounded and accounts of them can be found in the writings of Willis and Schlumberger. They seem less firmly based on observed fact and will not be discussed here.

\section{Conclusion}

The point which emerges from the case here reported is that thoracotomy should not be withheld where symptoms require it simply because of the age of the child. Thoracotomies have many times been performed on infants and are on the whole well tolerated. Thus, Gross (1946) has reported a pneumonectomy on a child 3 weeks old, and Twente (1950) removal of an intrathoracic tumour in a child aged 10 weeks. In the present instance the danger of leaving the tumour, in view of the progressively severe symptoms, was considered greater than the danger of operative intervention.

\section{Summary}

A case of anterior mediastinal teratoma causing symptoms in a child aged 10 days is reported. It was successfully removed with recovery of the patient. The pathogenesis is briefly discussed and a review of the entire literature on the subject since 1939 is included. A bibliography is also given.

My thanks are due to Mr. Gordon Cruickshank for permission to publish this case, and to Dr. D. B. Cruickshank for allowing me to make use of his pathological report.

\section{BIBLIOGRAPHY}

Aguilar, H. (1940). Publ. Cent. Invest. tisiol., B. Aires, 4, 309.

Anderson, R. L. (1950). Sth. Surg., 16, 1093.

Arbuckle, R. K. (1949). Amer. J. Roentgenol., 62, 52.

Beck, C. S. (1942). Ann. Surg., 116, 161.

Berman, J. K., Powell, J. P. and Hennessee, P. C. (1947). Amer. J. Surg., 74, 205.

Blades, B. (1946). Ann. Surg., 123, 749.

Bradford, M. L., Mahon, H. W. and Grow, J. B. (1947). Surg. Gynec. Obstet., 85, 467. Cabot, R. C. (1941). New Engl. J. Med., 224, 207. (Quoted

Collenberg, T. (1869). Quoted by Waldeyer (1871). Arch. Klin. Chir., 12, 843

Conklin, W. S. (1950). Dis. Chest, 17, 715.

Connolly, E. A. (1946). Neb. med. J., 31, 8.

Curreri, A. R. and Gale, J. W. (1949). Arch. Surg., Chicago, 58, 797.

Dann, D. S., Lockwood, I. H., Neibling, H. A. and Walker, J. W. (1945). Radiology, 44, 585.

De Bakey, M. E. and Creech, O. (1950). Texas J. Med., 46, 588.

Dominici, S. A. (1945). Gac. med. Caracas, 53, 158.

Fawcett, A. W. (1944). Brit. med. J., 2, 755.

Fralick, F. T. and Welsman, H. S. (1951). Dis. Chest, 19, 209.

Garcia Bengochea, J. B. and Pintos Pérez, J. (1946). Rev. clin. esp., 22, 208.

Gardner, F. V. (1950). Proc. roy. Soc. Med., 43, 481.

Gordon, J. A. (1827). Med.-Chir. Trans., 13, 12.

Gravano, L., Itoiz, O. A. and Bianchetti, S. L. (1943). Rev. Asoc. méd. argent., $57,878$.

Gross, R. E. (1946). Ann. Surg., 123, 229.

Heuer, G. J. and Andrus, W. DeWitt (1940). Amer. J. Surg., 50, 143.

Horowitz, I. (1947). Conn. St. med. J., 11, 978.

Joost, C. R. N. F. van, and Kopp, J. G. (1941). Geneesk. Tijdschr. Nedl.-Ind., 81, 969 . Quoted Wilson.

Katsurada, F. (1901). Beitr. path. Anat., 30, 179.

Kjaer, T. and Hansen, J. L. (1947). Nord. Med., 36, 2231

Lachance, R. (1946). Un. méd. Can., 75, 689.

Laipply, T. C. (1945). Arch. Path., Chicago, 39, 153.

Lloyd, M. S. (1948). Dis. Chest, 14, 396.

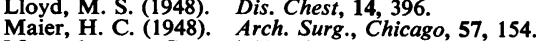

Massachusetts General Hospital Case Records (1948). New Eng. J. Med., 238, 706.

Needham, J. (1942). Biochemistry and Morphogenesis. Cambridge.

Rusby, N. L. (1944). J. thorac. Surg., 13, 169.

Schlumberger, H. G. (1946). Arch. Path., 41, 398.

Silveus, E. and Adams, R. (1947). Surg. Clin. N. Amer., 27, 596.

Tiitinen, E. (1949). Ann. Chir. Gyn. Fenn., 38, 185.

Twente, G. E. and Johnston, J. H. (1950). Miss. Doct., 28, 198.

Vervat, D. (1949). Maandschr. V. Kindergeneesk., 17, 116.

Wilson, S. J. and Cares, R. (1945). Arch. Path., 39, 113.

Willis, R. A. (1948). The Pathology of Tumours. 